\title{
Fertility Preservation: Save Our Hope for the Future It's Time to Re-think...
}

\author{
Budi Wiweko
}

Fertility preservation refers to every particular method in reproductive medicine performed in order to save reproductive function in special populations who are threatened of losing their reproductive capability. ${ }^{1-4}$ This approach is becoming very popular within the last five years due to the increasing number of cancer survivors among young females of reproductive age. ${ }^{4,5}$

Both chemotherapy and radiotherapy are toxic to the ovaries. Therefore, they may reduce the number of follicles, as determined by the patients' age, dosages, and type of chemotherapeutic agents utilized. Women receiving alkylating agents have an increased risk for loss of follicles by 3.8 times, while platinum based chemotherapeutic agents will have an increased risk of 1.8-fold. Older women need only lower dosages of chemotherapy in order to cause follicle loss, leading to infertility or ovarian insufficiency. 6,7

Before offering fertility preservation, doctors and patients should first determine the possibility of delaying cancer treatment. ${ }^{1,2}$ If possible, oocyte or embryo freezing is a preferable option after patients have underwent ovarian stimulation and oocyte retrieval. When the cancer treatment must be performed immediately, ovarian tissue or immature oocyte freezing is the best method for fertility preservation. ${ }^{1,8}$

Today, ovarian tissue vitrification has been established with very promising results, which has been demonstrated as being comparable to slow freezing method. ${ }^{4}$ This technique seems very simple, and is also easier and cheaper to be offered to patients. Indonesia has started ovarian tissue and pre-antral follicles vitrification since 4 years ago with satisfying results. ${ }^{9}$ A pilot study was done on cervical and breast cancer patients as research model. Regarding ovarian tissue and isolated pre-antral follicles vitrification, the results were adequately satisfactory. Follicle morphology and in vitro culture is one of the methods used to assess the survival of warmed-vitrified follicles.

Today, trans-disciplinary collaboration is a really important factor in supporting the establishment of the Indonesian Fertility Preservation Center. A working group should at least consist of oncologists (gynecology, surgeon, pediatric, internal medicine), reproductive endocrinologists, counselors, nurses, and lawyers. Our challenge and opportunity is to set up a "one stop service" for young female cancer patients and survivors to have children, genetically from their own oocytes.

Are we ready to help our patients in saving hope for their future?

\section{References}

1. Frydman R, Grynberg M. Introduction: Female fertility preservation: innovations and questions. Fertil Steril. 2016; 105(1): 4-5.

2. Kim J, Deal AM, Balthazar U, et al. Fertility preservation consultation for women with cancer: are we helping patients make highquality decisions? Reprod Bio Med Online 2013; 27(1): 96-103.

3. Linkeviciute A, Boniolo G, Chiavari L, et al. Fertility preservation in cancer patients: The global framework. Cancer Treat Rev 2014; 40(8): 1019-27.

4. Wallace WHB, Kelsey TW, Anderson RA. Fertility preservation in pre-pubertal girls with cancer: the role of ovarian tissue cryopreservation. Fertil Steril 2016; 105(1): 6-12.

5. Chung K, Donnez J, Ginsburg E, et al. Emergency IVF versus ovarian tissue cryopreservation: decision making in fertility preservation for female cancer patients. Fertil Steril 2013; 99(6): 1534-42.

6. Tomasi-Cont N, Lambertini M, Hulsbosch S, et al. Strategies for fertility preservation in young early breast cancer patients. Breast 2014; 23(5): 503-10.

7. Maltaris T, Seufert R, Fischl F, et al. The effect of cancer treatment on female fertility and strategies for preserving fertility. Eur J Obstet Gynecol Reprod Biol 2007; 130(2): 148-55.

8. Donnez J. Introduction: Fertility preservation, from cancer to benign disease to social reasons: the challenge of the present decade. Fertil Steril 2013; 99(6): 1467-8.

9. Wiweko B, Yuningsih T, Affandi B, et al. Ovarian tissue vitrification as a method for fertility preservation: A study of follicle number and morphology after vitrification. IVF Lite 2014; 1(3): 148. 